\title{
UM OLHAR FEMININO SOBRE A PERFORMANCE EXCESSO, PEDRAS E DORES
}

\author{
A FEMALE LOOK AT PERFORMANCE \\ EXCESS, STONES AND PAIN
}

\author{
UNA MIRADA FEMENINA AL PERFORMANCE \\ EXCESO, PIEDRAS Y DOLOR
}

\section{Marcella Nunes Rodrigues e Gisela Reis Biancalana}

Marcella Nunes Rodrigues Bacharela em Dança pela Universidade Federal de Santa Maria. Mestra e Doutoranda em Artes Visuais pelo Programa de PósGraduação em Artes Visuais da UFSM. Pesquisadora, Performer e Integrante do Grupo de Pesquisas Performances: Arte e Cultura, vinculado ao CNPQ. E-mail: marcellanunesrodrigues@gmail.com

Gisela Reis Biancalana

Doutora em Artes pela Unicamp com pós doutorado em Leicester, UK. Pesquisa Performance solo, coletivas e colaborativas em diálogo com a antropologia. Os focos dos

estudos estão na absorção e releitura de procedimentos metodológicos tais como a pesquisa de campo e a autoetnografia. As pesquisas são desenvolvidas no LAPARC (Laboratório de Pesquisa em Performance, Arte e Cultura) pelo grupo Performances: arte e cultura vinculado ao CNPQ e composto por doutorandos, mestrandos e ICs. É docente na UFSM e membro permanente do PPGART-UFSM. Organizadora da trilogia Discursos do Corpo na Arte. 


\section{Resumo}

Reflexões sobre o corpo e os espaços urbanos vem sendo foco de estudos a décadas precipitadas, também, pela intensa explosão demográfica detonada em meados do século XX. A arte, como campo de conhecimento, se debruça sobre estas questões refletindo, ainda, sobre a cadência das afetividades que podem arejar as relações humanas nesses contextos. O presente artigo busca edificar uma reflexão acerca da Performance intitulada Excesso, Pedras e Dores. O percurso investigativo foi concebido a partir de um olhar feminino das autoras em relação à experiência vivida que afetou a performer durante a ação realizada em um espaço alternativo. O procedimento de composição em arte foi sustentado pela abordagem metodológica autoetnográfica. A intervenção performativa no evento precipitou um espaço-tempo expandido ao viabilizar compartilhamentos de experiências singulares entre os participantes próprias das imbricadas ocupações empreendidas pela arte contemporânea.

Palavra-chave: Performance Arte, Gênero, Intervenção Urbana, Autoetnografia.

\section{Abstract}

Reflections on the body and urban spaces have been the focus of studies for decades precipitated, also, by the intense demographic explosion detonated in the middle of the 20th century. Art, as a field of knowledge, focuses on these issues, reflecting, also, on the cadence of affectivities that can air human relations in these contexts. This article seeks to build a reflection on Performance entitled Excess, Stones and Pains. The investigative path was conceived from a female perspective of the authors in relation to the lived experience that affected the performer during the action performed in an alternative space. The composition procedure in art was supported by the autoetnographic methodological approach. The performative intervention in the event precipitated an expanded space-time by enabling the sharing of singular experiences among the participants of the imbricated occupations undertaken by contemporary art.

KEYWORDS: Performance Art, Gender relations, Urban intervention, Autoetnography. 


\begin{abstract}
Resumen
Las reflexiones sobre el cuerpo y los espacios urbanos han sido el foco de los estudios durante décadas precipitados, también, por la intensa explosión demográfica detonada a mediados del siglo XX. El arte, como campo de conocimiento, se enfoca en estos temas, reflexionando también en la cadencia de las afectividades que pueden airear las relaciones humanas en estos contextos. Este artículo busca construir una reflexión sobre Performance titulada Excess, Piedras y Dolores. El camino de investigación fue concebido desde una perspectiva femenina de los autores en relación con la experiencia vivida que afectó al artista durante la acción realizada en un espacio alternativo. El procedimiento de composición en el arte fue apoyado por el enfoque metodológico autoetnográfico. La intervención performativa en el evento precipitó un espacio-tiempo expandido al permitir el intercambio de experiencias singulares entre los participantes de las ocupaciones superpuestas emprendidas por el arte contemporáneo.
\end{abstract}

Contrasenãs: Arte de performance, Relaciones de género, Intervención urbana, Autoetnografía

Reflexões sobre o corpo e os espaços urbanos como as grandes cidades, por exemplo, vem sendo foco de estudos a décadas. Esses debates são precipitados, também, pela intensa explosão demográfica detonada em meados do século XX. Na esteira desse pensamento, valores antigos sejam socioculturais, políticos, éticos, entre tantos, se enfrentam com a busca por valores instáveis necessitando, às vezes, da antiga segurança e das certezas às quais estávamos acostumados. De acordo com Oskar Negt (2002), a atual crise de orientação moral sucumbe à procura pelo indubitável. No frenesi dos espaços urbanos a cultura em constante mutação esbarra, então, em alguns pontos de fuga. Um deles é curvar-se à fé já que não se pode ter certeza de nada. O outro, encravado no sistema capitalista globalizado recorre, especialmente, a duas âncoras, entre outros aspectos aos quais não nos ateremos nesse texto. Um deles recai sobre a veracidade dos argumentos técnicos que geram certa segurança por serem oriundos de um fundamento científico funcional e utilitário. O outro é composto pelos conhecimentos que conferem bases econômicas sólidas às sociedades assegurando o giro do 
capital e sustentando os caprichos erosivos do mundo contemporâneo. Segundo Negt (2002, p. 17), estamos "num mundo intermediário, como aquele que o filósofo francês Durkheim definiu como vácuo moral".

O abismo amedrontador desse vácuo moral no qual se encontra esse mundo intermediário torna-se ambiente fértil para as resistências a postos. $A$ arte costuma ser um dos campos passíveis de experimentações que evocam questões socioculturais, especialmente de ordem política. Não nos referíamos aqui à política partidária, mas sim a uma perspectiva mais ampla do seu entendimento que remete às formas dos seres humanos de luta e organização no-pelo mundo. Também não são poucos os artistas que se debruçam sobre estas práticas. Neste contexto no qual arte, espaço tempo e política se fundem, o corpo presente assume sua potência vital como elemento forte e produtor de sentidos cada vez mais recorrente em ações que se inserem no cotidiano. Assim, um dos aspectos que tem se discutido na arte contemporânea é o fato do artista ser a própria arte, um corpo-arte. Sua presença em estado de arte pode ser criação e obra simultaneamente e adentrar em espaços tempos ora inimagináveis no contexto das artes em suas formas legitimadas a séculos.

Entre muitas manifestações que emergem do corpo em estado de arte, sobretudo nos interessa a Performance, passa a ocupar espaços-tempos diversificados acontecendo em qualquer lugar, em qualquer momento. A arte vem se fazendo presente não apenas em hora e lugar marcados e em espaços legitimados como teatros ou museus. Agora, a arte também permite, antes de tudo, situar no próprio corpo dos performers e no acaso do instante performativo, o espaço-tempo da obra. Esta peculiaridade da Performance desperta certo fascínio ao entendermos o corpo como obra já que ele não está apartado das criações, do espaço, do tempo e nem do público. Desse modo, o corpo em estado de arte passa a ser entendido como o próprio espaçotempo legitimador da obra não sendo apenas suporte ou veículo dela. Ele passa a ser experimentado adquirindo dinâmica e expandindo espaçostempos de si nas poéticas da arte contemporânea.

Portanto, a Performance vem gradativamente delineando contornos cada vez mais diversos na arte, propondo formas transversais e complexas 
de acordo com seus fazeres peculiares. Taylor (2011) aborda a Performance como uma arte viva pensada de modo plural, para além dos limites das linguagens convencionais. A Performance não depende de textos editoriais, não depende de diretor, podendo não depender de qualquer aparelho técnico que pertença aos museus ou aos teatros, pois não requer espaços convencionais. Ela necessita, em primeira instância, da performer e do público em ação, instável pela efemeridade, transpassando territórios à sua revelia. Deste modo, elas "funcionam como atos vitais" (TAYLOR, 2011, p. 20), que excluem qualquer tipo de enrijecimento, pulsando em fluxo contínuo.

Basmaun (1995) coloca os novos fazeres artísticos dos dias atuais como um momento de mobilização no qual as obras de arte produzem, ainda, um potencial coletivo em rede. Estas redes contaminam e são contaminadas em tempo integral, propagando e invadindo diversos espaços possíveis. Sob essa perspectiva a ação é também mediada trazendo, nesses casos, possibilidades de variações no percurso pré-estabelecido. Para Basmaun "a transversalidade é também um modo de construção" (1995, p. 8) no qual o acaso, os olhares, as visualidades, a mediação, juntos podem construir obras de arte descontínuas.

Sendo assim, tem sido instigante pensar a Performance como uma grande manifestação tentacular, refletindo o modo das pessoas se relacionarem. Desde meados do século passado até os dias de hoje, as relações humanas formam redes de contato fugazes, às vezes simultâneas, pulsantes e em constante movimento. Deste modo, essa dinamicidade que acompanha os movimentos cotidianos pode incitar o público a estar mais próximo deste contexto artístico vivo. Por outro lado, a proximidade da presença física dos corpos parece ampliar as relações arte-vida tornando-se uma estratégia também para promover debates sociais latentes. Por este motivo, as fronteiras entre arte e espaço-tempo se mostram intencionalmente diluídas. GOLDBERG (2006, p. 216) cita que a vivacidade da Performance também "explica seu apelo ao público que acompanha a arte [...], onde o envolvimento com artistas em carne e osso é tão desejável quanto a contemplação das obras de arte". O corpo em Performance é fluxo contínuo que não estanca questionamentos. Entre gritos, silêncio, imagens e todas as 
provocações possíveis, ele é vivo. Assim, o corpo-arte em Performance, entendido como a própria obra, transborda os discursos e as realidades nos espaços-tempos que ocupam. Algumas vezes, as Performances se assumem como atos de intervenção em ambientes urbanos interrompendo os espaçostempos cotidianos, amplificando-os e inserindo outros modos de operar também em direção a causas que desejam defender.

Sendo assim, este texto busca refletir sobre um percurso que atravessa a intervenção performativa urbana Caminho das Pedras e chega a um evento de psicologia com a Performance Excesso, Pedras e Dores. A discussão levantada aqui foca no caminho processual da criação percorrido pelo corpo atentando não para possibilidade de se ver dois trabalhos, mas com o intuito de ver um percurso único do corpo nos espaços-tempos ocupados da cidade. A reflexão passa, ainda, pela escolha metodológica ancorada na abordagem autoetnográfica que coloca as pesquisadoras amalgamadas ao foco investigativo co-existindo com ele e não discursando sobre ele. Portanto, foi a partir da ação Caminho das Pedras, inserida neste contexto interventivo, que nasceu a Performance: Excesso, Pedras e Dores apresentada neste artigo.

Este processo criador foi oriundo de um projeto guarda-chuva que engloba as ações de um grupo de pesquisas vinculado ao CNPQ. Este grupo, por sua vez, integra uma rede internacional de pesquisas que investiga processos criadores. A intervenção performativa urbana foi uma ação proposta durante as reuniões do grupo, no primeiro semestre de 2018, e que emergiu dos intercâmbios entre integrantes da rede de pesquisa. A ação se baseava na ida a campo e a intenção era que cada integrante do grupo, sozinho ou sozinha, percorresse um caminho definido individualmente e intitulado, nesse momento de Caminho das Pedras. No caminho, a ação consistia em recolher relatos de dores pessoais de desconhecidos que se dispusessem a abrir uma fenda no tempo de suas vidas para compartilhar suas dores vislumbradas a partir da metáfora das pedras que carregamos em nossas vidas. Após cada relato compartilhado, cada performer deveria pegar uma pedra que estivesse pela rua cujo tamanho, cor, textura fossem comparáveis às dores relatadas. Assim, os colaboradores dos performers nas 
ruas traziam ou apontavam para uma pedra que consideravam equivalente à sua dor. Posteriormente, as pedras eram reunidas e carregadas pelos performers no caminho de volta ao laboratório de criação no qual as dores foram compartilhadas entre os participantes do grupo.

A partir da proposta inicial lançada ao grupo pela coordenadora do laboratório e líder do grupo de pesquisas, começamos o caminho pelo centro da cidade ao encontro de mulheres. Para este trabalho escolhemos conversar com mulheres, pois somos pesquisadoras-artistas mulheres e este trabalho volta-se para o olhar próprio da mulher acerca dos modos de relações afetivas atuais. A mulher vem sendo alvo, por excelência, da dominação masculina há milênios em diversas culturas. Esta realidade assume inúmeras formas ao longo da história e mais recentemente tem sido acolhida, há algumas décadas, pelo campo de estudos de gênero. $\mathrm{Na}$ onda destes estudos implementados incessantemente por pensadoras, majoritariamente oriundas das ciências sociais e humanas, artistas mulheres têm desenvolvido poéticas que atentam para estas questões. Não são poucas as artistas que evocam os conflitos do universo feminino em seus trabalhos. Estes conflitos não são novos, mas ainda urgem por discussão e conquistas. Neste artigo, os encaminhamentos artísticos investigativos são feitos por pesquisadoras mulheres refletindo acerca das modificações nas relações humanas, em específico, as afetivas entre casais nas últimas décadas. Os estudos de gênero começaram a borbulhar com mais intensidade na década de noventa do século XX. Uma das pioneiras destes estudos é Scott (1990). Segundo a autora, gênero é a "organização social da diferença sexual percebida" (SCOTT, 1990, p.13). Torna-se necessário mencionar, sobretudo, que se desdobram uma série de debates sobre as diferenças no interior da discussão de gênero. As categorias de análise, atualmente, não se reduzem ao pensamento bipolarizado no masculino e no feminino absorvendo diversas outras orientações sexuais. Do mesmo modo, esses debates também estão sensíveis aos cruzamentos com reflexões sobre etnia, classe socioeconômica, entre tantas outras. A filósofa Judith Butler (2013) tem sido uma incansável pensadora e ativista nesse campo subvertendo ordem heteronormativa e desenvolvendo a teoria Queer como crescente campo 
discursivo da-sobre-pela as diferenças sexuais que transcende a concepção binária.

Neste contexto, debruçamo-nos sobre o sentimento de insegurança, instabilidade emocional, as dores provocadas pela entrada e utilização da cibercultura nos vínculos afetivos conjecturados sob perspectivas socioculturais femininas. Em todo o percurso, uma poética sobre afetividades se fez presente trazendo à tona um relato colhido em campo. Esse relato tornou-se mote na criação de Excesso, Pedras e Dores que, por sua vez, fez parte da série de Performances que compôs uma poética calcada nas afetividades femininas no mundo contemporâneo.

No espaço urbano aconteceu o encontro com pessoas no banco de uma praça mais retirada e a escuta de histórias de dores pessoais, compartilhadas por desconhecidas. Muitas dores passaram por nós naquela experiência. A Performance Excesso, Pedras e Dores, debruçou-se sobre o relato de uma destas dores que se tornou elemento propulsor da criação em laboratório. O relato foi colhido por uma das autoras deste texto, portanto ele será realizado, a seguir, em primeira pessoa.

Eu e uma das mulheres com quem conversei naquele dia estávamos sentadas, uma de frente para a outra. Ela olhava um pouco nos meus olhos e um pouco para o chão e relatou que a dor sobre a qual ela iria falar naquele instante era referente a depressão. Ela me contou que devido a problemas com seu marido e com sua família, foi percebendo uma tristeza imensa, uma desmotivação sem fim. Esta mulher que encontrei, fazia pouco tempo que havia se separado do seu esposo. O motivo foi uma traição que ocorreu por intermédio das redes sociais. A senhora relatou que quando descobriu o fato, não tinha forças para cumprir as tarefas do dia, não queria mais sair de casa, não desejava mais dividir a cama com seu parceiro. Ela queria somente a solidão do seu quarto, o silêncio da sua própria companhia e que só dormiria, se fosse possível. Até então, o relato desta senhora não havia me comovido tanto, pois, de um modo diferente, eu já havia escutado histórias de vida parecidas com a dela. Foi então o momento que sua voz embargou, seus olhos encheram d'água e o silêncio pairou naquela praça. Um minuto, dois, três, um suspiro longo e sua fala foi: "A depressão é como um câncer na alma. 
Dói! Dói! Dói! Dói tanto, até que não dói mais nada. Porque você não sente nada! Não sente mais nada! Te enchem de remédio para não sentir aquela dor e você acaba não sentindo mais nada!". Neste momento o silêncio foi meu. Neste mesmo silêncio, ela se levantou do banco, caminhou por volta da praça e voltou com uma pedra enorme, talvez a maior que ela pudesse carregar. Olhamo-nos mais uma vez, nos despedimos e eu fiquei com a sua pedra, que então passou a ser minha.

Neste dia, foram ouvidas cerca de vinte pessoas e foi despendido um tempo colecionando pedras, colecionando dores. No percurso empreendido, a última frase desta senhora pulsava em minha mente o tempo todo, e ainda pulsa. Não esqueci nem ao menos uma palavra daquele relato. No final do dia, me desfiz das pedras arrecadadas pelo caminho tentando também me desfazer das dores, mas a pedra desta senhora eu guardei no meu quarto. $O$ Caminho das Pedras foi uma experiência de entrega total. Após esta tarde, ao chegar em casa depois de caminhar e sentar com pessoas, suas dores, suas pedras, o silêncio ainda fazia parte do meu dia. Estava triste, mexida, meu estômago parecia doer. Não conversei muito com meus familiares, tomei um banho longo e enquanto a água escorria pelos meus cabelos eu chorava. Eu não somente tinha trazido a pedra daquela senhora para casa, tinha trazido sua dor também. A dor dela se embaralhava com dores pessoais semelhantes e com dores reconhecidas de pessoas próximas fazendo um denso e perturbador caldo de memórias. Ao mesmo tempo, chorar não me fazia mal. Eu tinha plena consciência de que se tratava de um processo em arte que objetivava a sensibilização na carne pelo carregar das pedras. Eu chorava e me sentia feliz! É difícil explicar em palavras essa sensação. A ação proposta trouxe-me a percepção, na carne, do fluxo de pessoas nas ruas, do tempo, entre outros fatores que foram detonadores de uma ação artística que já estava acontecendo naquele espaço-tempo da cidade primeiramente enquanto intervenção performativa urbana. Barja passa a entender as intervenções urbanas como uma manifestação artística quando elas

brotam em campos de dimensões diversas e variáveis muito abrangentes no ambiente da cultura artística contemporânea. Essas características híbridas da linguagem da intervenção urbana 
são capazes de ultrapassar, inclusive, as fronteiras da própria arte, projetando-se na vida cotidiana, como foi preconizado nas vanguardas históricas da Alta Modernidade do início do século XX, em que a arte deveria fazer parte da vida. (BARJA, 2002, p. 311)

A proposta constituiu uma intervenção performativa urbana tornando aquela ida a campo em uma ação artística. Daqui para frente, esse trabalho criador desprende-se da partilha com a rede internacional, que continua com este grupo em seu percurso próprio, para adentrar em investidas individuais dos performers do grupo. Assim, cada um dos integrantes do laboratório foi instigado a manter acesa a chama da experiência vivida buscando materialidades diversas que pudessem continuar evocando a vida dos relatos que mais chamaram a atenção de cada um. Estas materialidades poderiam ser textos, mitos, objetos, enfim, um arsenal de coisas que remetessem aos relatos selecionados. A proposta subsequente foi criar Performances individuais a partir desta experiência. O trabalho de criação em ateliê, então, passou a percorrer trilhas pessoais semeadas pelos relatos das pessoas abordadas em seus enfrentamentos de vida. $O$ percurso advindo gerou práticas que são produções singulares de indivíduos artistas-performers, sobre nós, sobre eles, sobre o caminho. Assim foi encontrada, na história reportada acima, o assunto que instigou a construção da Performance Excesso, Pedras e Dores calcada nas questões de gênero. Foi eleita, então, a dor daquela mulher em tratamento para a depressão como elemento norteador do processo criador. $O$ objeto trazido para o ateliê foi uma cama de casal com seus apetrechos conhecidos tais como travesseiros, cobertas além de muitas pedras.

A criação propunha indagar em que momento os problemas conjugais de traição, em grande parte das vezes cometida por homens, levam uma pessoa a desenvolver depressão e como esta doença afeta as sensações do corpo e as relações interpessoais do sujeito. Vale salientar que não compartilhamos da visão romântica de que a traição é exclusiva do gênero masculino. Apenas trata-se de admitir que, devido aos efeitos, ainda presentes, da nossa cultura patriarcal colonizada por valores eurocêntricos, os homens ainda dominam esse campo não apenas como ação, mas no 
discurso da permissividade justificada por uma suposta necessidade biológica que seria própria dos homens. O relato da traição via internet fez pensar no quão este ambiente é facilitador da vida em diversos aspectos. No caso das amplas possibilidades de trocas internáuticas, sabemos que elas não são, obviamente, a causa destas traições, mas podem ser ambientes facilitadores. No mundo contemporâneo, ao mesmo tempo que muitas imagens são expostas, poucas coisas são realmente vistas. Esta obra despiu o que cobre a dor, pensamento levantado durante a idealização da Performance Excesso, Pedras e Dores. As questões que moveram a criação dessa Performance também nasceram do desejo de permitir que o público percebesse, de algum modo, uma dor velada. Grande parte dos espaços contemporâneos são mascarados, o que permite às pessoas apresentarem somente o desejado por elas mesmas. Em um mundo no qual as coisas querem mostrar-se belas, de ângulos perfeitos, comidas apetitosas aos olhos, perfumes que mascaram odores naturais, amor que transborda nas fotos, parece não haver espaço para o que é dolorido, triste, monótono e para misérias. para misérias. Um mundo onde a transitoriedade é perpétua e contínua, no qual as multipossibilidades estão escancaradas diante de pessoas virtuais, promovese uma infinidade de excessos. Isso inclui a possibilidade, cada vez mais frequente, das pessoas assumirem multifacetados tipos de vidas, entre as virtuais e as reais. Tal fato acontece, talvez, também pela instantaneidade com que as conexões são feitas e desfeitas. Impressiona o ritmo acelerado das mudanças tecnológicas e os consequentes impactos culturais que elas provocam no mundo (SANTAELLA, 2003, p.7). Com os inúmeros dispositivos disponíveis no mercado, as realidades são também virtuais, e o mundo pode estar na sua casa e ao mesmo tempo está em seu lugar de origem. As realidades de espaço e tempo sofrem mudanças significativas, e a continuidade histórica é repensada pelo viés da não linearidade e não causalidade dos acontecimentos.

Explorar esse assunto nos fez atentar para a sensação de instabilidade que as relações humanas contemporâneas estão sujeitas com a chegada de diferentes configurações socioculturais que se delineiam nos dias atuais. É notória a carência das referências duradouras e estáveis nas relações 
interpessoais, já que muitas relações passam a não se fixarem, pelo contrário, são efêmeras, móveis e assim como começam repentinamente acabam. Muitas vezes, não há a necessidade de explicações ou prestação de contas. Nas redes virtuais, especificamente, também se tornou difícil fixar-se a um único tipo de identidade, pois a mobilidade compõe e recompõe processos identitários fluídos plurais mutantes. Bauman compara as relações atuais "com uma balsa frágil, pois quando a insegurança sobe a bordo, perde-se a confiança, a ponderação e a estabilidade da navegação" (2004, p. 31). Este pensamento é justificado ao pensar neste tipo de relação como uma característica incidente dos dias atuais. Esse tipo de relação rizomática, fluida, veloz, ao mesmo que liga o indivíduo a muitas pessoas, faz dele um ser comum nesta grande rede. Ao abordar esta questão exaustivamente em diversos campos de saberes, acreditamos que ainda há um longo caminho de discussões a ser percorrido. Os comportamentos sociais em rede, desde o ponto de vista ético, estético, político, legal, entre outros, tem sido um dos objetos de estudo que atrai inúmeros pesquisadores devido aos desafios dos atuais modos de ser-estar-pensar-agir-sentir no mundo contemporâneo.

Deste modo, os desdobramentos da pesquisa de campo e da etnografia na abordagem metodológica autoetnográfica foi escolhido não apenas por enfocar o olhar presente da artista neste trabalho, tanto na relação estabelecida com as pessoas encontradas no caminho, quanto no modo de enxergar, em espaços públicos, a relação afetiva das pessoas. A escolha se dá, especialmente, por incluir a pesquisadora como sujeito e foco da pesquisa simultaneamente. Fortin entende que "a autoetnografia se caracteriza por uma escrita do 'eu' que permite o ir e vir entre as experiências pessoais e as dimensões culturais (...)" (FORTIN, 2009, p. 83). Aqui, evidencia-se como este procedimento metodológico escolhido absorve a artista pesquisadora, em todo o percurso do processo criador amalgamando passado, presente e futuro. Para Versiani (2002 p. 70), por sua vez, a autoetnografia "se opõe aos pressupostos de multiplicidade, na tentativa de dar conta da diversidade e da particularidade, do singular e do coletivo". As experiências pessoais de vida são reativadas desde as estadas em campo pelos contatos estabelecidos durante o Caminho das Pedras, até o momento da Performance Excessos, 
Pedras e Dores no evento relatado a seguir. O trabalho ainda impulsiona a ação para o futuro à medida que cada presentação da Performances vem incitando-nos a fazer outra, em outro lugar, com outros grupos de pessoas. $O$ momento de Caminho das Pedras se alarga e se faz presente em tempo integral, já que as experiências advindas das relações socioculturais, pessoais e de outros, entrecruzadas, podem atuar como reativadoras de situações emblemáticas do meio em que vivemos diariamente.

Foi assim que se materializou a realização da Performance Excesso, Pedras e Dores. Desde o começo, uma das opções para sua realização foi o desejo de não a leva-la um público especificamente das artes. $O$ desejo de levar a Performance para um local diferente do contexto cotidiano imerso nas artes surgiu com a oportunidade de apresenta-la em um evento da área de psicologia. O evento tinha o objetivo de abordar o cuidado e a atenção com a saúde mental de formas alternativas fomentando a integração entre os campos de saberes e seus efeitos na constituição das políticas públicas de saúde. A partir deste momento ficou decidido que levaríamos Excesso, Pedras e Dores para fora da zona de conforto, para outro espaço, no qual o público não era das artes, mas composto por profissionais, pesquisadores, estudantes e professores das áreas de Psicologia, Terapia Ocupacional, Enfermagem, Pedagogia, Educação Especial, entre outras. Deste modo, retomando o processo de criação da Performance, instigou-nos o modo como a pesquisa ganhou corpo após a intervenção performativa urbana Caminho das Pedras, assim que os objetos foram imaginados, agrupados e experimentados em ateliê de criação, bem como no momento de configurarse como ação performativa e entregar-se à relação com o público.

A Performance foi realizada na tarde do dia 06 de dezembro de 2018, no hall do prédio onde aconteceu o evento. A opção por estar neste lugar do hall, um local de passagem do prédio, foi porque ali haveria bastante circulação das pessoas envolvidas no evento. Para a realização da Performance recolhemos e carregamos pedras, juntamente com colegas do grupo que acompanharam o decorrer do processo até a ação ir a público. Esta Performance trouxe uma cama (figura 1) como objeto artístico e o colchão coberto de pedras. Os tamanhos das pedras eram variados já que, não 
necessariamente, as dores mais visíveis são as maiores. Havia, ainda, pedras pequenas espalhadas entre as maiores. Muitas vezes, uma pedrinha quase invisível pode incomodar mais do que uma grande e visível. Com a cama montada, o colchão um pouco sujo, o travesseiro de pedra, a ação inicia. A performer inevitavelmente pensa no mal-estar detonado pelas circunstâncias específicas vividas por ela e pelas outras pessoas, advindas dos relatos ouvidos que envolviam as relações humanas, sejam virtuais ou não. Deitar sobre as pedras e pensar naquelas dores incrustadas na carne lembrando, também, da dor causada por carregar pedras e por deitar sobre elas tanto em laboratórios de criação quanto naquele momento, neutraliza instantaneamente a função daquele espaço-tempo cotidiano. $\mathrm{O}$ instante abre uma fresta no cotidiano com a imagem da performer na cama empedrada para evocar a fragilidade propositalmente deflagrada pela constelação de experiências.

Figura 1: Performance Excessos, Pedras e Dores, 2018.

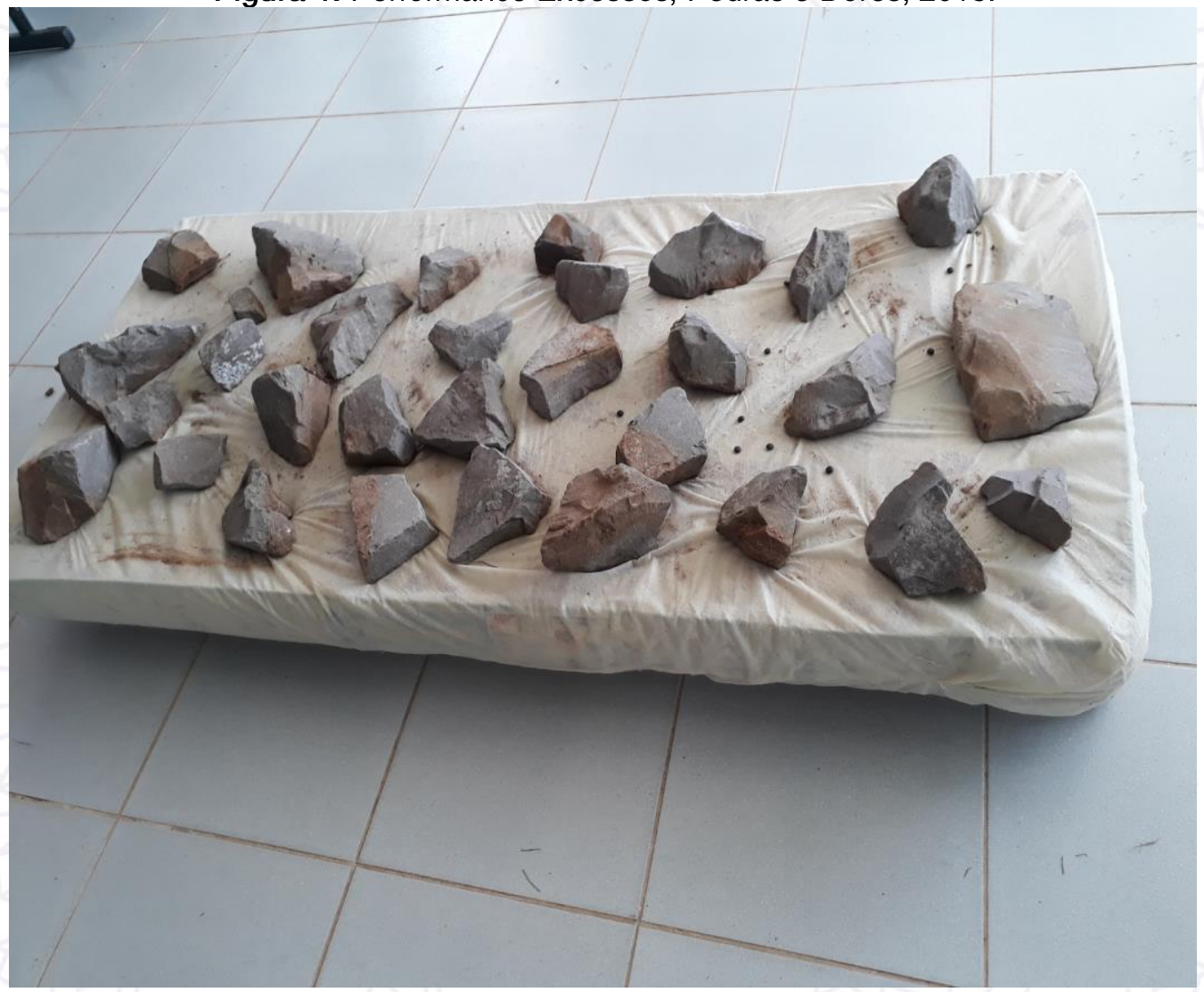


Então, com a performer deitada na cama de pedras, aos poucos 0 público vai se aproximando. Na mão contrária de toda velocidade a qual o mundo está exposto, optou-se pela imobilidade, pelo silêncio e por desligar alguns instantes relembrando a fala daquela mulher na praça da cidade. A escuta de barulhos altos e velozes em decorrência das conversas vai suspendendo o tempo e se acalmando. Ali deitada, a performer permanece com os olhos fixos no teto do espaço no qual se encontra. Inicialmente, a pretensão era que a Performance durasse um longo período, uma vez que evidenciava a inação, a ausência de impulsos de vida corroídos pela dor. Contudo, acontece uma surpresa advinda da ação empreendida pelas pessoas que estavam no local. Bastou que uma pessoa do público iniciasse uma ação sobre a ação performativa que ela pode provocar um efeito dominó que desloca por completo a intensão primeira. Por mais estruturada que estejam as Performances, no instante do contato com o público, elas estão sujeitas a interferências. Neste caso, as interferências modificaram muito o trabalho que havia sido projetado no princípio.

Em poucos instantes, logo após o começo da Performance, uma pessoa levantou-se do seu lugar e trocou a pedra que estava debaixo da cabeça da performer por uma almofada. Neste momento passou uma onda de ansiedade no corpo em estado de arte. Enquanto estava no início da ação, a performer sentia as mãos daquela pessoa no pescoço, vagarosamente por causa da dor que as pedras infligem, foi possível virar e olhar nos olhos dela. Era um rapaz, que devolveu o olhar e sentou-se novamente. A partir de então, pouco a pouco, pessoas foram saindo de seus lugares para remover as pedras que estavam embaixo da performer (figura 2). 


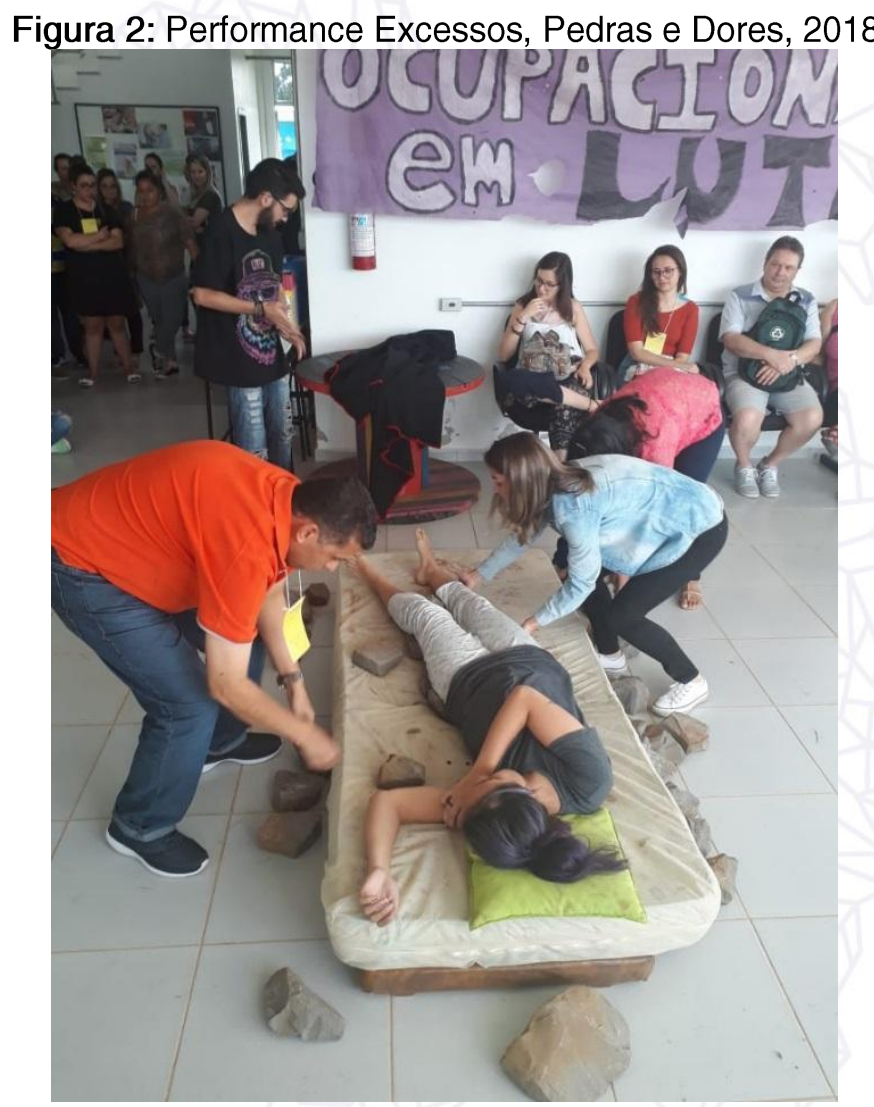

A sensação do estado corporal nesta Performance foi indescritivel. A interação do público de uma forma tão ativa na Performance modificou-a por inteiro. A ação da Performance era a paralisia do corpo, porém, as pessoas participantes do evento, que estavam naquele hall no momento da Performance, não permitiram. Ainda é possível ouvir a voz de uma senhora que levantou-se olhando para todos que estavam no local e disse aos outros que ainda assistiam: "Vocês não vão fazer nada?". Ela começou a arrancar, com força, várias pedras daquele colchão. Neste momento, as lágrimas começaram a escorrer dos olhos da performer. A sensação de estar deitada, com pessoas mexendo no corpo performativo, escolhendo as pedras que iriam retirar foi de aconchego, de partilha silenciosa de afetos, de evocar o sensível. As lágrimas eram um misto de alívio das dores com as pedras marcando a carne e de conforto pelo acolhimento, uma vez que, as pedras eram dores de muitas pessoas.

O final da Performance foi, do mesmo modo que todo o decorrer da mesma, se definindo pelo contato com o público. Quando se acabaram as 
pedras, a performer permanece ainda deitada olhando um pouco para o nada, outro pouco para alguém específico entre as pessoas que estavam ali, quando de repente uma mulher a levanta daquele colchão, a abraça e também se sensibiliza com lágrimas.

A proposta inicial escapa do controle, permite colocar-se à deriva alterando a ideia inicial do trabalho. A proposta era que a performer ficaria deitada por um tempo mais longo na cama de pedras, mas isso não ocorreu encharcando o ambiente de partilhas sensíveis. Isso permitiu a composição visual que ocorreu pela ação deliberada por aquele corpo performativo. $\mathrm{O}$ corpo-arte compartilhado, comunicando, questionando, deu voz e transbordou determinados discursos e realidades em quase total estado de imobilidade.

Deste modo, esta Performance ensejou uma poética carregada de sensibilidade e promotora de uma cadência coletiva de afetos. Assim, foi elaborada uma poética que remete à ambiguidade entre instabilidade e estabilidade quando a proposta é deitar sobre uma cama de pedras que machucam. A ação também recai sobre a monotonia, envolvendo questões emocionais alimentadas por sentimento de insegurança, solidão, não existência quando a ação da performer é permanecer quase imóvel naquela cama. A Performance também perpassa questões relacionadas a incerteza, a dúvida e a sensação de que até as conquistas são transitórias. Com isso, pensamos que o mundo contemporâneo precisa entender-se na sua estabilidade precária, volátil, no risco dos acasos, na maleabilidade. Enfim, nada

pode ser conhecido com segurança e qualquer coisa que seja conhecida pode ser conhecida de um modo diferente - um modo de conhecer é tão bom, ou tão ruim (e certamente tão volátil e precário) quanto qualquer outro. Apostar, agora, é a regra onde a certeza, outrora, era procurada, ao mesmo tempo que arriscar-se toma o lugar da teimosa busca de objetivos. Desse modo, há pouca coisa, no mundo, que se possa considerar sólida e digna de confiança, nada que lembre uma vigorosa tela em que se pudesse tecer 0 itinerário da vida de uma pessoa. (BAUMAN, 1998, p.36).

A partir deste trabalho, foi possível evidenciamos o quanto a intervenção performativa urbana Caminho das Pedras, citada anteriormente, pulsou na Performance idealizada e no corpo performativo. Caminho das 
Pedras aproximou a perfomer de outras pessoas e de si mesma, das suas memórias, das vivências e da presença deste manancial de experiências na pesquisa. Ela foi o caminho encontrado para revolver sensibilidades adormecidas no processo criador de Excesso, Pedras e Dores, implodindo a dimensão sociocultural dos acontecimentos estudados.

Assim, permitimos que a experiência de compartilhar arte em espaços diferentes do habitual promovesse um colapso no fazer artístico estável mostrando o atual caráter móvel e expandido dos seus percursos e possibilidades. Deste modo, percebemos que as ideias iniciais foram se ramificando para um estado evanescente. $\mathrm{Na}$ fugacidade da experiência compartilhada, a artista-pesquisadora experimentou, na pele, como a Performance pode ser atravessada pelo público e pelo espaço. Aqui compreendemos que a pesquisa vai acontecendo de forma processual e pode ir se movendo fluidamente de acordo com os processos que ocorrem entre os agentes indissociavelmente. $O$ trânsito de trocas que acontecem em lugares que aglutinam pessoas circulando, ou seja, lugares que incitam as relações interpessoais em Performance são extremamente sedutores. Esses lugares, devido à peculiaridade de cada um, viabilizam compartilhamentos de experiências singulares durante as imbricadas ocupações empreendidas pela arte contemporânea.

\section{Referências bibliográficas}

BARJA, Wagner. INTERVENÇÃO/TERINVENÇÃO - A arte de inventar e intervir diretamente sobre o urbano, suas categorias e o impacto no cotidiano. Revista Rizoma.Net, 2002. Disponível em:

https://mail.google.com/mail/u/0/\#inbox?projector=1. Acesso em: 06 jun. 2019. BASMAUN, Ricardo. “E agora?”. Colaboração. s/v, p. 84 - 93, 1995.

BAUMAN, Zygmunt. O mal-estar da Pós-Modernidade. Rio de Janeiro: Jorge Zahar, 1998.

BAUMAN, Zygmunt. Amor líquido: sobre a fragilidade dos laços humanos. Rio de Janeiro: Jorge Zahar, 2004. 
BUTLER, Judith. Problemas de gênero: feminismo e subversão da identidade. Rio de Janeiro: Civilização Brasileira, 2013.

FORTIN, Sylvie. Contribuições possíveis da Etnografia e da auto-etnografia para a pesquisa na prática artística. Revista Cena, n. 7, 2009.

GOLDBERG. RoseLee. A arte da performance: do futurismo ao presente. São Paulo: Martins Fontes, 2006.

NEGT, Oskar. Cidade e Cultura: esfera pública e transformação urbana. (org. Vera Pallamin) São Paulo: Estação Liberdade, 2002.

SANTAELLA, Lucia. Culturas e Artes do Pós Humano: da cultura das mídias à cibercultura. São Paulo: Paulus, 2003.

SCOTT, Joan W. Gênero: uma categoria útil de análise histórica. Educação e Realidade, vol. 16, n 2, Porto Alegre, 1990.

TAYLOR, Diana. Introducción Performance, teoria y práctica. In: TAYLOR, Diana; FUENTES, Marcela (Edits.). Estudiosavanzados de performance. México: Fondo de Cultura Económica, 2011.

VERSIANI, Daniela Beccaccia. Autoetnografia: uma alternativa conceitual. Porto Alegre: Letras, 2002. 